\title{
Research on assessment technology method of high efficiency air cleaners
}

\author{
Huang $\mathrm{Jin}^{1}$, Shen $\mathrm{Hao}^{2}$, Zhang Xiaoxin ${ }^{1}$, Lin Ling ${ }^{1}$, Li Zhenhai ${ }^{3}$, Chen Jun ${ }^{4}$, Wu Wei ${ }^{5}$, Wang Baozhu \\ ${ }^{1}$ China National Institute of Standardization, Beijing 100191, China \\ ${ }^{2}$ Shanghai metrological testing technology research institute \\ ${ }^{3}$ Tongji University \\ ${ }^{4}$ Guangdong media refrigeration equipment co., LTD \\ ${ }^{5}$ Green Electric Appliances, INC. of Zhuhai \\ ${ }^{6}$ Vkan Certification \& Testing Co., Ltd
}

\begin{abstract}
In the face of the increasingly severe situation of air pollution, the research on evaluation technology and method of high-efficiency air pollution control equipment in China is being advanced. This paper discusses the background and significance of the research on high efficiency air cleaner evaluation techniques and methods, and introduces the General Ideas and principles of the research on high efficiency air cleaner evaluation techniques and methods, the technical methods of high efficiency air cleaner evaluation are established, including the evaluation object and scope of application, basic requirements of high efficiency air cleaner qualitative evaluation, quantitative evaluation requirements of key evaluation indicators, testing, calculation and evaluation methods, etc., the application of the research results of air cleaner will facilitate the production and consumption of air cleaner products.
\end{abstract}

\section{Research background}

\subsection{Air pollution treatment demand}

Currently as the deep advancement of China industrialization and urbanization, energy and resource consumption increase continuously, China environment condition is still severe, the compound air pollutions that are mainly consisted of fine particulate matter PM2.5 and ozone $\mathrm{O} 3$ have become more obvious. Take the example of Beijing-Tianjin-Hebei region, air quality has improved a little but the concentration of PM2.5 is still high, and is higher than the air quality class II for Beijing-TianjinHebei and surrounding areal. Meanwhile the concentration of ozone $\mathrm{O} 3$ in critical area has increasing trend and it becomes the major pollutant especially in summer and fall in some cities.

In recent years, to promote sustainable economic development, and environment treatment and protection, and also push energy saving work, China releases series industry planning and policies to support and guide air pollutions treatment in China, and promote a formal and healthy industry development. The series energy saving and environment protection related industry policies and planning such as the State Council released "The action plan for preventing and controlling air pollution", "Energy conservation and emission reduction comprehensive plan in the 13th Five-Year Plan", "Development plans for energy conservation and environmental protection industries in the 13th Five-Year Plan" and "Proposals for the 14th Five-Year Plan and the Vision Goals of 2035" that were released at the first year of "the 12th Five-Year Plan", "the 13th Five-Year Plan", and "the 14th Five-Year Plan", all specified clearly requirement of air pollution treatment. In Jun 2018, the State Council issued "Notification of three years plan to get blue sky" that has clearly specified "with three years effort, reduce the amount of main air pollutions a lot, reduce the greenhouse gas emission coordinately, further reduce concentration of fine particulate matter (PM2.5), obviously reduce heavy pollution days, improve air quality significantly, and enhance people's happiness of blue sky.

\subsection{Increasing product quality demand}

In the face of increasingly severe air pollution, in addition to the treatment of air pollutants in key industries such as thermal power, steel, cement, petroleum and chemical industry, China is also gradually strengthening the evaluation and improvement of the quality, safety, energy saving and environmental protection characteristics of

\footnotetext{
* Corresponding author: huangjin@cnis.ac.cn
} 
daily used indoor air pollution prevention equipment and products. Air cleaner, as a professional indoor environment health product to improve and solve indoor air pollutions, gradually develops to a kind of environment protection products that can governance indoor air pollutions such as fine particulate matter, microorganism, formaldehyde and volatile organic gas, and it could be used in bedroom, office, public places, industrial factories, hospitals and other indoor environments. In recent years, due to the widespread awareness of smog and PM2.5, air cleaners have gradually been recognized by the public, and with the improvement of people's health awareness, they have rapidly become one of the consumer's daily household appliance. However, what follows is that domestic and foreign large-scale production and sales enterprises have entered the air cleaner industry, and the whole industry is in the stage of sustained and high-speed development. The explosive growth brings the issues of market un-formal competition and product quality uneven and other problems, not only make consumers confusing when choose excellent products, but also be negative to popularize the reasonable and correct use of air cleaner to consumers. Therefore, the market and consumers both increase requirements for the improvement of the comprehensive performance of air cleaner products, such as quality, safety, energy saving and environmental protection.

In fact, as early as 2016, the General Office of the State Council of China issued the "Implementation of Quality Development Program 2016 Action Plan" clearly proposed to deeply carry out quality improvement action, air cleaners as indoor air pollution control special environmental protection equipment is regarded as one of key consumer goods that need to improve quality. In February 2016, the National Development and Reform Commission issued "guidance on promoting green consumption", air cleaner products are still on the list of key products, and encourage production enterprises to promote technical innovation, but also encourage consumers could have scientific and correct judgement and choice for the products on the market to improve the public consciousness of energy conservation and environmental protection. In view of this, carry out the evaluation technique for highly efficient air cleaner timely and do research on related technical standards at right timing, reference relevant existing international and national standards, and put forward a higher performance requirement, these can effectively guide the air cleaner production enterprises to improve product design and manufacturing level, formalize market access threshold, and can significantly improve the efficient environmental protection equipment, the market share of the products and services, so as to encourage the advanced and eliminate the backward ones.

\section{The general idea and principle of research on evaluation technology and method of high efficiency air cleaner}

\subsection{Closer integration with current national environmental protection regulations and industrial policies}

Research of highly efficient air cleaner evaluation methods give full consideration to the requirements of current national environmental protection laws, regulations and policies, including related environmental protection industry policies, the development and utilization of resources and energy and saving policy, ecological civilization construction and policy for the control of air pollution, and air pollution control technology equipment demonstration, restrict eliminate etc.

\subsection{Coordination with the current national and industrial standards of air cleaners}

When determining the evaluation index of HEPA, this study extensively referenced the technical requirements set in the existing national and industrial standards of related products, coordinated with the relevant domestic standards that have been released and implemented, and tried to be in line with the relevant international standards and regulations to ensure the uniformity and coordination of the standards. The national standards and industry standards for Air Cleaners released in 2015 mainly include: GB/T 18801-2015[1] "Air cleaner" and HJ2544-2016 ${ }^{[2]}$ "Technical Requirements for Environmental Label Products Air Cleaner". In this study, while taking into account the performance indicators of the products in the above standards, the evaluation indicators of the high efficiency characteristics of the air cleaner are also appropriately added, such as the evaluation technical requirements of the characteristic index of energy efficiency attenuation, to make the high efficiency characteristics of the Air Cleaner more prominent.

\subsection{General requirements of following evaluation method for high efficiency air pollutions control equipment}

In the field of air pollutant control and environmental protection equipment, China has initially formed a relatively complete standard system that are mainly consist of basic general standards, testing method standards, product standards and management evaluation standards, and relevant performance testing and performance evaluation methods have also been solidified into relevant technical standards. The research on the evaluation technology and method of high efficiency air pollutant control equipment involves the high efficiency evaluation of major single environmental protection equipment in the fields of dust removal, desulfurization, denigration, decarbonization, fog removal, deodorization, VOC control, indoor air management and other related 
subdivision fields. According to the previous top-level design of the research on the evaluation technology method of high efficiency air pollutants control equipment, China has completed the research on the efficient evaluation technology method of key environmental protection equipment such as ESP, bag dust collector and electric bag composite dust collector from 2014 to 2016. Therefore, this study continues to follow the overall framework requirements of the Evaluation Method for High Efficiency Air Pollutant Control Equipment, and establishes an evaluation index system for the air cleaner equipment in terms of technical performance, energy saving, environmental protection, safety and reliability, etc., and establishes an operational evaluation method.

\subsection{Establish Principle of evaluation method and evaluation index system}

2.4.1 To evaluate whether the air cleaner has reached the high efficiency level, we should not only evaluate the characteristics of the equipment itself, but also need to evaluate the management level of the production enterprise. Through the application of the research achievement, it should be able to effectively regulate the air cleaner's production, guide the enterprises to get technological progress, and lead the market consumption and use of high-efficiency air cleaners.

2.4.2 The construction of evaluation index system and the selected index should include technical performance, energy saving, environmental protection, safety and reliability, etc. When select indicators, we should consider comprehensiveness, concise, highlighted key points, and should be scientific and reasonable, strong operability and easy access to index data.

2.4.3 The principle of combining qualitative and quantitative indicators should be adopted. Qualitative indicators should be easy to verify while quantitative indicators should be measurable. With the science and technology progress and industry development, both quantitative and qualitative evaluation indicators will be continuously expanded.

2.4.4 It should be clearly specified for evaluation index testing method, testing theory, data collection and calculation.

\section{High efficiency air cleaner evaluation technical method establishment}

\subsection{Evaluation object and appliable scope}

\subsubsection{Evaluation object}

Due to the increasingly diversified and complicated of air cleaner target pollutants, this research defines the evaluation object in the view of product features and application requirements that refers to "a kind of electrical equipment that could get circulation purification indoor air by purification unit, and could remove some particle, gaseous contaminants and microbial."

\subsubsection{Scope of application}

Currently in China, air cleaners are mainly used for household and similar purposes, with a single-phase rated voltage of $220 \mathrm{~V}$. Except for industrial, medical, treatment and other professional purposes, the operating voltage is not more than $250 \mathrm{~V}$. For cleaning air quantity assessment of solid particles, we could reference American association of household electrical appliances (AHAM) reference standard, and could also base on some pollutions' particularly prominent in the urban environment air pollution contribution rate, and has the long-term characteristic comparing with gaseous pollutants and microbial contamination, meanwhile, the purification capacity is a basic performance of current air cleaner and evaluation method is mature. Considering these characteristics, the object air cleaners of this research is suitable for single-phase rated voltage not exceeding $250 \mathrm{~V}$, and particulate matter clean air amount $(30 \sim 800) \mathrm{m} 3 / \mathrm{h}$, and not for industrial, medical, automobile, governance and other professional application design and corrosive, explosive and other special environment using air cleaner products, it only selects ion technology of air purification products, as well as the air duct type air purification device, a new fan and other similar air purification equipment. Through the establishment of the evaluation index system, the air purification that meets the following "basic requirements for qualitative evaluation" and "quantitative evaluation requirements for key evaluation indexes" is the high efficiency air cleaner.

\subsection{Qualitative evaluation basic requirement}

As the producers of high efficiency air cleaners, first of all, they should meet the requirements of relevant environmental protection laws, regulations and standards, establish and maintain the quality management system and environmental management system; at the same time, the following requirements of appearance quality, electronic parts, safety, electromagnetic compatibility, hazardous substance content and operation instructions of the air cleaner are put forward:

3.2.1 For appearance quality, there should be no defects such as fingerprints, scratches, bubbles and shrinkage holes; The main components material should be safe, nontoxic, harmless, odor free, non-secondary pollution, and durable; From the product design side, propose the air cleaner producer to choose safe, environmental protection, healthy and durable materials to manufacture highefficiency air cleaner.

3.2.2 The selected electronic components should be safe and reliable, and the unit security requirements should conform to the GB 4706.1 $1^{[3]}$ "Household and similar 
electrical safety Part 1: general requirements", 4706.45 ${ }^{[4]}$ GB regulation in "Household and similar electrical appliances safety - the special requirements of air cleaner". From the point of the basic security of electrical appliances product, air cleaners' electronic components and the whole unit are both required to satisfy the safety and reliability requirements.

3.2.3 For electromagnetic compatibility, it should meet regulations in GB 4343.1-2009 [5] "household appliances, electric tools and similar apparatus of EMC requirements Part 1: emission", GB 4343.2-2009 [6] "household appliances, electric tools and similar apparatus of EMC requirements Part 2: immunity ", from the view of the reliability of electrical products electromagnetic compatibility, it's required that there is no electromagnetic interference with other devices around the product itself, no affect on other equipment normal operation, and also not affected by the surrounding electromagnetic interference and to ensure the normal work.

3.2.4 In terms of the content of harmful substances, it should meet the provisions of GB/T 26572-2011 ${ }^{[7]}$ "Requirements of Restricted Substances amount in Electrical and Electronic Products" and "Administrative Measures for Restricted Use of Hazardous Substances in Electrical and Electronic Products". From the perspective of product materials environmental protection, it is required that the products materials meet the corresponding requirements of national environmental protection.

3.2.5 For application instruction, the performance characteristics of air cleaners are required to be used as the application instructions of appliances, and it shall comply with the provisions of GB 5296.2-2008 ${ }^{[8]}$ "Consumer Goods Instructions Part 2: Household and similar electrical appliances". From the view of product labeling standardization, the basic requirements of consumer goods electrical products shall be met.

\subsection{Key evaluation index quantitative evaluation requirements}

The quantitative indicators in the evaluation technical method of high energy air cleaner should be selected by the characteristics of air cleaner, and should be the key evaluation indicators that have a significant impact on the quality assurance, reliable operation, energy saving and environmental protection of high energy air cleaner. These key evaluation indicators are composed of level I and level II indicators. Among them, the first-level indicators mainly include four aspects "technical performance, energy efficiency, environmental protection, operation safety and reliability", and a number of refined secondlevel indicators are selected for each category of indicators. Ensure that the evaluation value of the second-level indicators is in the advanced level of the domestic air cleaner industry. Specific evaluation indexes, evaluation methods and index value requirements are shown in Table 1 .

Table1. High efficiency air cleaner quantitative evaluation index

\begin{tabular}{|c|c|c|c|}
\hline number & $\begin{array}{l}\text { Level I } \\
\text { evaluation } \\
\text { index } \\
\end{array}$ & $\begin{array}{l}\text { Level II evaluation } \\
\text { index }\end{array}$ & $\begin{array}{l}\text { evaluation } \\
\text { method and } \\
\text { requirement }\end{array}$ \\
\hline \multirow{4}{*}{1} & \multirow{4}{*}{$\begin{array}{l}\text { Technical } \\
\text { performance } \\
\text { index }\end{array}$} & $\begin{array}{l}\text { Particulate matter } \\
\text { clean air volume }\end{array}$ & $\begin{array}{l}\text { Tested value } \geq \\
\text { nominal value }\end{array}$ \\
\hline & & $\begin{array}{l}\mathrm{PM}_{2.5} \text { clean air } \\
\text { volume } \\
\text { (when nominal } \\
\text { function is available) }\end{array}$ & $\begin{array}{l}\text { Tested value } \geq \\
\text { nominal value }\end{array}$ \\
\hline & & $\begin{array}{l}\text { Purification } \\
\text { efficiency of gaseous } \\
\text { pollutants } \\
\text { (when nominal } \\
\text { function is available) }\end{array}$ & $\geq 80 \%$ \\
\hline & & $\begin{array}{l}\text { Antibacterial rate } \\
\text { (when nominal } \\
\text { function is available) }\end{array}$ & $\geq 99 \%$ \\
\hline \multirow{3}{*}{2} & \multirow{3}{*}{$\begin{array}{l}\text { Energy } \\
\text { efficiency } \\
\text { index }\end{array}$} & Standby power & $\leq 2.0 \mathrm{~W}$ \\
\hline & & $\begin{array}{l}\text { Energy efficiency } \\
\text { ratio }\end{array}$ & $\geq 8.00 \mathrm{~m}^{3} /(\mathrm{W} \cdot \mathrm{h})$ \\
\hline & & $\begin{array}{l}\text { attenuation rate of } \\
\text { energy efficiency } \\
\text { ratio }\end{array}$ & $\leq 4.0$ \\
\hline \multirow{7}{*}{3} & \multirow{7}{*}{$\begin{array}{l}\text { Environment } \\
\text { protection } \\
\text { index }\end{array}$} & $\begin{array}{l}\text { Percentage of ozone } \\
\text { concentration }\end{array}$ & $\leq 3 \times 10^{-6}$ \\
\hline & & TVOC concentration & $\leq 0.08 \mathrm{mg} / \mathrm{m}^{3}$ \\
\hline & & $\mathrm{PM}_{10}$ concentration & $\leq 0.04 \mathrm{mg} / \mathrm{m}^{3}$ \\
\hline & & \multirow{4}{*}{$\begin{array}{l}\text { Noise } \\
\text { (Sound power level) }\end{array}$} & $\begin{array}{l}50 \quad \leq \text { CADR } \\
(\quad \text { Nominal } \\
\text { value }) \leq 150: \\
\leq 52 \mathrm{~dB}(\mathrm{~A})\end{array}$ \\
\hline & & & $\begin{array}{l}150<\text { CADR } \\
(\quad \text { Nominal } \\
\text { value }) \leq 300: \\
\leq 58 \mathrm{~dB}(\mathrm{~A})\end{array}$ \\
\hline & & & $\begin{array}{l}300<\text { CADR } \\
(\quad \text { Nominal } \\
\text { value }) \leq 450: \\
\leq 63 \mathrm{~dB}(\mathrm{~A})\end{array}$ \\
\hline & & & $\begin{array}{l}450<\text { CADR } \\
(\quad \text { Nominal } \\
\text { value }) \leq 800: \\
\leq 67 \mathrm{~dB}(\mathrm{~A})\end{array}$ \\
\hline \multirow{5}{*}{4} & \multirow{5}{*}{$\begin{array}{l}\text { Safe and } \\
\text { reliable } \\
\text { operation } \\
\text { index }\end{array}$} & \multirow[t]{2}{*}{ Ultraviolet radiation } & $\begin{array}{l}200 \mathrm{~nm} \quad \sim \\
280 \mathrm{~nm}: \quad \text { total } \\
\text { irradiance } \leq 0.00 \\
3 \mathrm{~W} / \mathrm{m}^{2} \quad ; \\
\text { Spectral } \\
\text { irradiance } \leq 10^{-} \\
{ }^{5} \mathrm{~W} /\left(\mathrm{m}^{2} \cdot \mathrm{nm}\right)\end{array}$ \\
\hline & & & $\begin{array}{l}250 \mathrm{~nm} \\
400 \mathrm{~nm}:\end{array}$ \\
\hline & & $\begin{array}{l}4 / 5000 \\
\text { Applicable area }\end{array}$ & $\begin{array}{l}\text { Nominal } \\
\text { value }=\text { calculate } \\
\text { d value }\end{array}$ \\
\hline & & \multirow{2}{*}{$\begin{array}{l}\text { Particulate filter } \\
\text { replacement } \\
\text { maintenance cycle } \\
\text { (specified condition) }\end{array}$} & $\begin{array}{l}\text { One time filter } \\
\text { replacement } \\
\text { cycle: } \\
\geq 26 \text { weeks }\end{array}$ \\
\hline & & & $\begin{array}{l}\text { Reusable filters } \\
\text { for a single } \\
\text { maintenance } \\
\text { cycle: } \geq \\
16 \text { weeks }\end{array}$ \\
\hline
\end{tabular}




\subsection{Testing method, calculation and evaluation method}

For the main evaluation index, including: clean air quantity, purify air particles PM2.5, gaseous pollutants purification efficiency, an antibacterial rate, standby power, energy efficiency ratio, attenuation rate of energy efficiency ratio, ozone generation concentration, TVOC concentration, PM10 concentration, noise, ultraviolet radiation, filter replacement maintenance cycle, etc., high efficient air cleaner evaluation technique method provides the corresponding test method for each of them; At the same time, the detailed calculation methods of clean air volume of particulate matter, clean air volume of PM2.5 particulate matter, purification efficiency of gaseous pollutants, antibacterial rate, energy efficiency ratio, attenuation rate of energy efficiency ratio, applicable area, filter replacement and maintenance cycle are given, which are not detailed here. Finally, the air cleaners that meet the basic requirements of qualitative evaluation and the requirements of quantitative evaluation indicators in Table 1 can be evaluated as high efficiency air cleaners.

\section{Conclusion}

High efficiency air cleaner refers to those cleaners with "advanced technical performance, leading energy efficiency, superior environmental performance and safe and reliable operation ". The evaluation method of HEPA follows the general requirements of the Evaluation Method for HEPA control equipment. The proposed Highly efficient air cleaner evaluation methods proposed basic requirements and key evaluation index qualitative evaluation requirements are advanced, and their testing, calculation and evaluation method are scientific and reasonable that reaches the international leading level, which can effectively help air cleaner products and green industrial to develop toward green, low carbon and circulation industry direction. In the future, with technological progress and industrial development, the evaluation index system of HEPA will be further refined and improved.

\section{References}

1. GB/T 18801-2015 Air cleaner

2. HJ2544-2016Technical requirements for environmental label products, air purifier

3. GB 4706.1Household and similar electrical appliances-Safety Part 1:General requirements

4. GB 4706.45Household and similar electrical appliances - Safety - Particular requirements for aircleaning appliances

5. GB 4343.1 - 2009Electromagnetic compatibility requirements for household appliances,electric tools and similar apparatus-Part 1: Emission

6. GB 4343.2 - 2009Electromagnetic compatibility-Requirements for household appliances, electric tools and similar apparatus--Part 2:Immunity--Product family standard

7. GB/T 26572 - 2011Requirements of concentration limits for certain restricted substances in electrical and electronic products

8. GB 5296.2 - 2008Instructions for use of products of consumer interest--Instructions for use of household and similar electrical appliances 